\title{
Survey of Blood Collection Centers and Implementation of Guidance for Prevention of Transfusion-Transmitted Zika Virus Infection — Puerto Rico, 2016
}

\author{
Amber M. Vasquez, $\mathrm{MD}^{1,2}$; Mathew R.P. Sapiano, $\mathrm{PhD}^{2}$; Sridhar V. Basavaraju, $\mathrm{MD}^{2}$; Matthew J. Kuehnert, $\mathrm{MD}^{2}$; Brenda Rivera-Garcia, $\mathrm{DVM}^{3}$
}

Since November 2015, Puerto Rico has reported active mosquito-borne transmission of Zika virus (1). Because of the potential for Zika virus to be transmitted through transfusion of blood components, and because a high percentage of persons infected with Zika virus are asymptomatic (2), the Food and Drug Administration (FDA) recommended that blood collections cease in areas of the United States affected by active vector-borne transmission of Zika virus until laboratory screening of blood donations or pathogen reduction technology (PRT)* for treatment of blood components can be implemented (3). To inform efforts to maintain the safety and availability of the blood supply in Puerto Rico, CDC, in collaboration with the Puerto Rico Department of Health, conducted a rapid assessment of blood collection and use on the island. A total of 139,369 allogeneic red blood cell (RBC) units, ${ }^{\dagger}$ 45,243 platelet units, and 56,466 plasma units were collected in or imported to Puerto Rico during 2015, and 135,966 allogeneic RBC units, 13,526 therapeutic platelet units, ${ }^{\circledR}$ and 25,775 plasma units were transfused. Because of the potential for local Zika virus transmission in areas with a competent mosquito vector (4), other areas of the United States should develop plans to ensure local blood safety and adequacy. Blood collection organizations and public health agencies should collaborate to maintain the safety and availability of local blood supplies in accordance with FDA guidance.

Before this survey, no estimates of blood collection and use in Puerto Rico were available. The survey, conducted during

\footnotetext{
* Chemical and/or ultraviolet light treatment to achieve reduction of risk for transfusion-transmitted infection. PRT is currently approved by the Food and Drug Administration (FDA) only for plasma and platelets derived from apheresis methods. It is not FDA-approved for red blood cells.

$\dagger$ Allogeneic blood components are collected from donors for transfusion into another person.

$\S$ A unit of platelets prepared for transfusion from pooled individual whole blood derived platelet units.
}

February 10-24, 2016, included all blood collection centers performing local collections and importing blood components from the mainland United States for routine clinical use, as well as hospitals performing transfusions in Puerto Rico during 2015. The survey was based on a modified version of the 2015 National Blood Collection and Utilization Survey administered by CDC on behalf of the U.S. Department of Health and Human Services (5), in which U.S. territories have previously not been included. The survey included questions about donor blood collection methods and product types, importation of blood products for routine use, blood use, and extent of PRT implementation for platelets and plasma. Questionnaires were electronically distributed to the laboratory manager or medical director of each facility and were self-administered. Total collections and transfusions of whole blood, whole blood derived (WBD) RBC, platelet, plasma, and cryoprecipitate units (including total numbers of blood components imported from the continental United States), as well as RBC, platelet, and plasma units collected via apheresis methods were tabulated. Estimates of transfusion were weighted for nonresponse using inpatient surgical volume (the average number of surgical procedures performed annually at a hospital) as a proxy for the amount of blood used annually, and $95 \%$ confidence intervals were estimated.

All $12(100 \%)$ blood collection centers and 51 (91.1\%) of 56 hospitals performing transfusions responded to the survey. During 2015, a total of 82,381 whole blood units were reported to have been collected in Puerto Rico. These whole blood units yielded WBD components, including 80,431 allogeneic RBC units, 32,753 individual platelet units, 47,055 plasma units, and 4,615 cryoprecipitate units. RBCs, platelets,

\footnotetext{
A medical technology that involves the withdrawal of blood from a donor, removal of one or more blood components (e.g., plasma or platelets), and transfusion of the remaining blood back into the donor.
}

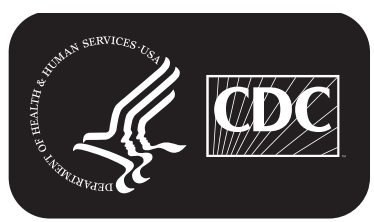

U.S. Department of Health and Human Services Centers for Disease Control and Prevention 
and plasma collections using apheresis methods were reported in much fewer numbers than those derived from whole blood (Table 1). PRT was used only to treat apheresis platelets, and constituted 1,403 (25.6\%) of the 5,467 apheresis platelet collections. An additional 52,411 RBC units, 7,023 apheresis platelet units, 7,906 plasma units, and 2,651 cryoprecipitate units were imported from the continental United States for routine use in 2015. A total of 135,966 allogeneic RBC units, 13,526 therapeutic platelet units, and 25,775 plasma units were transfused in 2015 (Table 2). Only 511 (36.4\%) of the 1,403 PRT-treated platelet units were transfused by hospitals in 2015 .

\section{Discussion}

No blood transfusion-transmitted cases of Zika virus infection have been confirmed in Puerto Rico or the U.S. mainland (4); however, Zika virus nucleic acid was detected retrospectively in $2.8 \%$ of asymptomatic blood donors during a 2013-2014 Zika virus disease outbreak in French Polynesia $(G)$, and transfusion-transmitted Zika virus infection has been reported in Brazil ( 7 ), where substantial Zika virus transmission is occurring. Because a large percentage of persons infected with Zika virus are asymptomatic (2), the risk for transfusiontransmitted Zika virus infection in Puerto Rico and other areas of the United States and its territories is of concern.

In Puerto Rico, the majority of whole blood units and blood component units collected during 2015 were collected locally, placing a large proportion of the local blood supply at potential risk for transfusion-transmitted Zika virus infection. Whereas PRT is FDA-approved for plasma and apheresis platelets, and could be used to treat portions of the blood supply in accordance with FDA guidance, a lower than expected proportion of the platelet supply was derived from apheresis methods in Puerto Rico compared with the continental United States, where in 2013, 95\% of all platelets were collected via apheresis (5); this difference might have been related to cost of implementation of apheresis methods in Puerto Rico. In addition, PRT is not FDA-approved for whole blood or RBCs, the most commonly transfused WBD component. These factors resulted in a risk for critical blood shortages as local blood collections in Puerto Rico were recommended to cease on March 1, 2016, in accordance with FDA guidance, until a nucleic acid screening test could be implemented for blood collections under investigational protocols beginning on April 4, 2016 (8).

The results of this survey were used to guide a federally supported coordinated effort to address the blood supply and safety challenges in Puerto Rico, which included importation of all blood components from the continental United States at a volume sufficient to meet the demand projected from the 2015 estimates, beginning on March 5, 2016 (9). Local collections
TABLE 1. Number of units of blood and blood components collected by all 12 of the country's blood collection centers or imported from the continental United States for routine clinical use - Puerto Rico, 2015

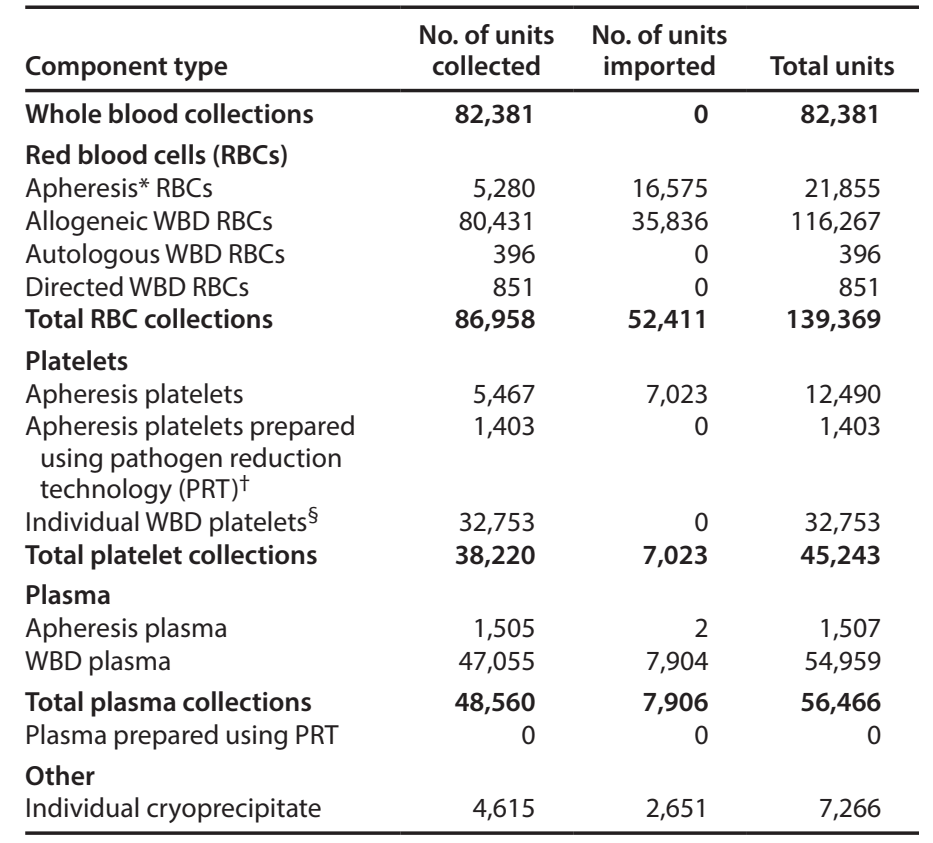

Abbreviation: $\mathrm{WBD}=$ whole blood derived.

* A medical technology that involves the withdrawal of blood from a donor, removal of one or more blood components (e.g., plasma or platelets), and transfusion of the remaining blood back into the donor.

+ Chemical and/or ultraviolet light treatment to achieve reduction of risk for transfusion-transmitted infection. PRT is currently approved by the Food and Drug Administration (FDA) only for plasma and platelets derived from apheresis methods. It is not FDA-approved for red blood cells.

$\S$ WBD platelets were reported as individual units. These units are pooled to result in a standard adult dose. The average pool size for whole blood derived platelets was 5.8 individual doses.

resumed in Puerto Rico on April 2, 2016, after FDA approved blood donations in the United States to be screened for Zika infection using an investigational nucleic acid test developed by Roche Molecular Systems (Branchburg, New Jersey) (8). In addition, efforts to implement PRT for apheresis platelets and plasma collections in Puerto Rico are currently under way, and evaluation trials to determine safety and efficacy of investigational PRT for RBCs are in planning stages.

The findings in this report are subject to at least three limitations. First, survey data were self-reported by facilities and could not be independently verified. Second, although the survey response rate was high, results were limited by missing responses to some questions, leading to uncertainty regarding the estimates. Finally, although English language assistance was available to respondents, each of whom was contacted directly by a Spanish-speaking team member to ensure receipt of the survey and inquire about the need for assistance, the survey instrument was written in English, which might have 
TABLE 2. Weighted estimates of the number of units of blood and blood components transfused and number of hospitals $(N=56)$ responding to the survey - Puerto Rico, 2015

\begin{tabular}{|c|c|c|c|}
\hline Component type & $\begin{array}{l}\text { No. of units } \\
\text { transfused* }\end{array}$ & $\begin{array}{l}\text { No. of } \\
\text { hospitals } \\
\text { responding }\end{array}$ & $(95 \% \mathrm{Cl})$ \\
\hline \multicolumn{4}{|l|}{ Whole blood units } \\
\hline Allogeneic $^{\dagger}$ & 0 & 27 & - \\
\hline Directed $\S$ & 0 & 28 & - \\
\hline Autologous" & 22 & 28 & $(0-68)$ \\
\hline \multicolumn{4}{|l|}{ Red blood cells } \\
\hline Allogeneic & 135,966 & 47 & $(110,856-161,075)$ \\
\hline Directed & 2,338 & 32 & $(0-6,288)$ \\
\hline Autologous & 357 & 36 & $(29-684)$ \\
\hline \multicolumn{4}{|l|}{ Platelets } \\
\hline Whole blood derived (WBD**) & 22,054 & 31 & $(4,768-39,339)$ \\
\hline Apheresis $^{\dagger \dagger}$ platelets & 9,724 & 44 & $(5,590-13,857)$ \\
\hline $\begin{array}{l}\text { Apheresis platelets prepared } \\
\text { using pathogen reduction } \\
\text { technology (PRT) })^{\S \S}\end{array}$ & 511 & 44 & $(0-1,278)$ \\
\hline \multicolumn{4}{|l|}{ Plasma } \\
\hline Total & 25,775 & 46 & $(15,935-35,615)$ \\
\hline Plasma prepared using PRT & 0 & 23 & - \\
\hline
\end{tabular}

Abbreviation: $\mathrm{Cl}=$ confidence interval.

* Weighted for nonresponse in a population of 56 hospitals.

t Collected from donors for transfusion into another person.

$\S$ Donations intended for a specific recipient.

" Donations by individuals for their own use, often for an elective procedure or planned transfusion.

** WBD platelets were reported as individual units. These units are pooled to result in a standard adult dose. The average pool size for whole blood derived platelets was 5.8 individual doses.

${ }^{+\dagger}$ A medical technology that involves the withdrawal of blood from a donor, removal of one or more blood components (e.g., plasma or platelets), and transfusion of the remaining blood back into the donor.

$\S \S$ Chemical and/or ultraviolet light treatment to achieve reduction of risk for transfusion-transmitted infection. PRT is currently approved by the Food and Drug Administration (FDA) only for plasma and platelets derived from apheresis methods. It is not FDA-approved for red blood cells.

affected the interpretation of questions by staff members in blood collection centers and hospitals; the impact on the survey findings is not known.

The risk for transfusion-transmitted Zika virus infection presents a current challenge to the safety and availability of the blood supply in Puerto Rico and an emerging threat to other areas of the United States, where Zika virus might spread via mosquito-borne transmission, particularly given the risk for clinical complications associated with infection, including Guillain-Barré syndrome and congenital abnormalities in infants born to women infected during pregnancy (10). Because of the high rate of asymptomatic infection (2), blood donor screening without a laboratory test is insufficient for identifying infected donors in areas with active transmission. Interventions to prevent transfusion-transmitted Zika virus infection in areas of the United States that do not have active mosquito-borne transmission include donation deferral for those who have had Zika virus infection (deferral for 4 weeks after symptom resolution) or symptoms suggestive of Zika

\section{Summary \\ What is already known about this topic?}

Because of the potential for transfusion-associated transmission of Zika virus, the Food and Drug Administration (FDA) has recommended deferral of blood donors in affected U.S. areas until blood donations can be screened by nucleic acid testing or blood products can be subjected to FDA-approved pathogen reduction technology (PRT). FDA has recommended that whole blood and blood components for transfusion be obtained from U.S. areas without active Zika virus transmission.

What is added by this report?

Puerto Rico is experiencing active Zika virus transmission and also performs local blood collections. Therefore, Puerto Rico is the first U.S. area to need to comply with FDA guidance. Historically, Puerto Rico has also imported blood from the U.S. mainland for routine purposes. Outsourcing of blood components from unaffected areas might not be feasible if there is widespread Zika virus transmission in heavily populated areas of the continental United States. Therefore, local blood collections should be maintained through the use of nucleic acid screening or PRT.

What are the implications for public health practice?

Importation of blood products from nonaffected areas might serve a role in prevention of transfusion-transmitted Zika virus. An approved laboratory test for blood donor screening and implementation of PRT are critical for compliance with FDA guidance and to ensure a safe and sustainable blood supply. Blood collection organizations and public health organizations need to collaborate to prepare for blood safety and adequacy challenges that might arise if Zika virus transmission spreads in the United States.

virus infection during the past 4 weeks, those who have had sexual contact with a person with Zika virus infection or who has traveled to, or resided in, an area with active Zika virus transmission during the prior 3 months, and those who have traveled to areas with active transmission of Zika virus during the past 4 weeks (3). In areas with current mosquito-borne Zika virus transmission, importation of blood components from unaffected areas is recommended until nucleic acid testing is implemented or PRT, as applicable, is adopted.

Outsourcing of blood components from unaffected areas might not be feasible if there is widespread Zika virus transmission in heavily populated areas of the continental United States. Therefore, it is important to maintain local blood collections in the continental United States. The availability of safe blood is a critical need for health care, and collaboration between blood collection organizations and health departments is essential to comply with FDA guidance, including implementation of laboratory testing of blood donations or use of PRT with plasma units and apheresis platelets. 


\section{Acknowledgments}

Yvonne Cruz, Division of STD Prevention, CDC; Joaquin Rueda, Division of Global Migration and Quarantine, CDC; participating blood collection organizations and health care facilities, Puerto Rico.

\footnotetext{
${ }^{1}$ Epidemic Intelligence Service, CDC; ${ }^{2}$ Division of Healthcare Quality Promotion, National Center for Emerging and Zoonotic Infectious Diseases, CDC; ${ }^{3}$ Puerto Rico Department of Health.

Corresponding author: Amber M. Vasquez, avasquez@cdc.gov, 404-718-1613.
}

\section{References}

1. Thomas DL, Sharp TM, Torres J, et al. Local transmission of Zika virus-Puerto Rico, November 23, 2015-January 28, 2016. MMWR Morb Mortal Wkly Rep 2016;65:154-8. http://dx.doi.org/10.15585/ mmwr.mm6506e2

2. Duffy MR, Chen TH, Hancock WT, et al. Zika virus outbreak on Yap Island, Federated States of Micronesia. N Engl J Med 2009;360:253643. http://dx.doi.org/10.1056/NEJMoa0805715

3. Food and Drug Administration. Recommendations for donor screening, deferral, and product management to reduce the risk of transfusion-transmission of Zika virus. Silver Spring, MD: US Department of Health and Human Services, Food and Drug Administration; 2016. http://www.fda.gov/downloads/ BiologicsBloodVaccines/GuidanceComplianceRegulatoryInformation/ Guidances/Blood/UCM486360.pdf
4. CDC. Zika virus: transmission \& risks. Atlanta, GA: US Department of Health and Human Services, CDC; 2016. http://www.cdc.gov/zika/transmission/

5. Chung KW, Basavaraju SV, Mu Y, et al. Declining blood collection and utilization in the United States. Transfusion 2016. In press.

6. Musso D, Nhan T, Robin E, et al. Potential for Zika virus transmission through blood transfusion demonstrated during an outbreak in French Polynesia, November 2013 to February 2014. Euro Surveill 2014;19:20761. http://dx.doi.org/10.2807/1560-7917.ES2014.19.14.20761

7. Reuters. Brazil reports Zika infection from blood transfusions. February 4, 2016. http://www.reuters.com/article/us-health-zika-brazil-blood-idUSKCN0VD22N

8. Food and Drug Administration. FDA allows use of investigational test to screen blood donations for Zika virus. Silver Spring, MD: US Department of Health and Human Services, Food and Drug Administration; 2016. http://www.fda.gov/NewsEvents/Newsroom/ PressAnnouncements/ucm493081.htm

9. US Department of Health and Human Services. HHS ships blood products to Puerto Rico in response to Zika outbreak. Washington DC: US Department of Health and Human Services; 2016. http://www.hhs. gov/about/news/2016/03/07/hhs-ships-blood-products-puerto-ricoresponse-zika-outbreak.html

10. Cao-Lormeau VM, Blake A, Mons S, et al. Guillain-Barré syndrome outbreak associated with Zika virus infection in French Polynesia: a case-control study. Lancet 2016. Epub February 29, 2016. http://dx.doi. org/10.1016/S0140-6736(16)00562-6

Readers who have difficulty accessing this PDF file may access the HTML file at http://www.cdc.gov/mmwr/volumes/65/wr/mm6514e1. htm?s_cid=mm6514e1_w. Address all inquiries about the MMWR Series, including material to be considered for publication, to Editor, MMWR Series, Mailstop E-90, CDC, 1600 Clifton Rd., N.E., Atlanta, GA 30329-4027 or to mmwrq@cdc.gov. 